\begin{abstract}
Explicit modelling of factor markets clarifies two fundamental aspects of the New Keynesian Phillips Curve (NKPC). First, we clarify the relationship between output and marginal cost. Second, for the NKPC in inflation-output space, we identify the key stochastic influences on inflation without recourse to ad hoc cost or excess demand shocks. The econometric implementation of this clarified NKPC, based on Campbell (1987), allows us jointly to derive inflation as a forecast of future variables and infer the degree of price stickiness in real-world data. Our approach clarifies the empirical successes and failures of the NKPC.
\end{abstract}

JEL Classification: E10; E20; E31.

Keywords: Inflation; Phillips Curve; Marginal Cost; Output Gap; Factor markets; Price Stickiness. 


\title{
Output, Inflation and The New Keynesian Phillips Curve ${ }^{1}$
}

\author{
Jagjit S. Chadha ${ }^{2}$ \\ Charles Nolan ${ }^{3} 4$ \\ University of Cambridge \\ University of Durham
}

This Version: February 2002

\section{Introduction}

Understanding the interaction between output and inflation at the business cycle frequencies remains a central concern of macroeconomists. However, even using models that should be well-suited to capturing this relationship, such as sticky-price stochastic general equilibrium models, e.g., Yun (1996), Woodford (2000), progress has been surprisingly modest. Part of the problem seems to be that New Keynesian models generally imply a direct relationship not between inflation and output, but between inflation and marginal cost. Specifically, the supply-side of these models is characterized by an equation linking contemporaneous inflation to anticipated inflation and the contemporaneous costs of production. To generate an expression linking inflation and output, authors invoke a proportional relationship between marginal cost and the output gap arguing that because inputs are scarce marginal cost is an increasing function of output. ${ }^{56}$

Unfortunately, as an empirical framework for explaining inflation over the business cycle, the 'New Keynesian Phillips Curve' (NKPC) in inflation-output space has not been particularly successful. As Gali and Gertler (1999) note, “...it is often difficult to detect a statistically significant effect of real activity on inflation using the structural formulation implied by the theory, when the measure of real activity is an output gap." And they rightly add: "Failure to find a significant short-run link

\footnotetext{
${ }^{1}$ Acknowledgement: We are grateful for constructive comments from colleagues and seminar participants. A version of this paper has been presented at Cambridge University, Cardiff University Business School and HM Treasury.

${ }^{2}$ Clare College, Cambridge. Address: Department of Applied Economics, Austin Robinson Building, Sidgwick Avenue, University of Cambridge, Cambridge CB3 9DE, UK. Tel: +44 1223 335242. E-mail: jagjit.chadha@econ.cam.ac.uk. http://www.econ.cam.ac.uk/dae/people/chadha/

${ }^{3}$ Department of Economics and Finance, 23/26 Old Elvet, Durham DH1 3HY. Tel +44 191 374 7273. E-mail: Charles.Nolan@durham.ac.uk. http://www.dur.ac.uk/charles.nolan/index.html

${ }^{4}$ Corresponding author.

${ }^{5}$ See the insightful review of the literature in Clarida, Gali and Gertler (2000).

${ }^{6}$ See also Rotemberg and Woodford (1999) on the relationship between marginal cost and output.
} 
between real activity and inflation is unsettling for the basic story." Other authors have gone further with, for example, Mankiw and Reis (2001) arguing that "the NKPC...is completely at odds with the facts". ${ }^{7}$ However, Gali and Gertler (1999) demonstrate that shifting the focus from output and inflation back to marginal cost and inflation re-establishes the link between short-run inflation dynamics and a measure of real activity. They conclude that the purely forward-looking model of the inflation process provides a "reasonable first approximation of reality", even though, as they recognize, their preferred model is rejected on statistical grounds. In an important contribution Sbordonne (2001) argues, therefore, that the NKPC "yields a prediction about inflation and output only insofar as standard measures of the 'output gap' are good measures of marginal cost". Again, she demonstrates employing an econometric approach closely related to that in this paper, that the basic NKPC in inflation-marginal cost space can track the US data impressively well.

However, attempting to understand the short to medium-run behavior of inflation and its relationship to output has a long tradition in macroeconomics. There are a number of reasons for this but two in particular stand out. First, as Taylor (1993) and many subsequent analysts demonstrate, a large part of the behavior of monetary authorities in many countries can be understood as a reaction to deviations of inflation and output from trend or target values. Second, Woodford (2000) has recently clarified the importance of the relationship between these two macro-aggregates and the welfare of the representative agent. Taken together these two points act to re-establish the need to understand the joint paths of inflation and output in response to shocks, ultimately in order to consider the question of optimal policy design. As a practical matter many authors often work with stripped down versions of these sticky price models, comprising of a few key structural equations plus an equation representing the monetary policy rule. Clarifying the foundations of these structural equations, and particularly the time series properties of the stochastic shocks to these equations, is clearly important if these small models are not to be misleading. However, we appear to have come full circle; we would like to understand the interaction between inflation and output, but merely replacing the marginal cost term in the NKPC with output (or the output gap) is unlikely to

\footnotetext{
${ }^{7}$ See also the discussion in Ball (2000)
} 
yield much insight.

In this paper we argue that explicit modelling of factor markets is necessary to understand the relationship between inflation, marginal cost and output. Whilst it is possible, and popular, to derive the NKPC without modelling factor markets in which case for 'marginal cost' read 'marginal disutility of labor' - we show that modelling the factor markets is central to understanding two important aspects of the NKPC. First, there is the relationship between output and marginal cost. We demonstrate below that if output, or the output gap, alone was substituted for marginal cost it would indeed be difficult to capture the inflation dynamics in the real world data. This is essentially a problem of omitted variables. The NKPC is an aggregate version of an optimality condition governing the individual firm's optimal price. That optimal price is evidently not merely a function of demand conditions. Consequently, if the level of demand for the individual firm is not the only determinant of prices, there is no reason, at the aggregate level, to expect a tight relationship between output/aggregate demand and inflation. Modelling the factor markets explicitly identifies the missing variables. These turn out to be wages, the capital stock and total factor productivity. And identifying these variables reveals clearly why simply adding a 'shock' term to a NKPC in inflation-output space is unlikely to be of much help when taking the model to the data.

Second, and relatedly, endogenizing capital accumulation identifies the dominant stochastic influences on the path of inflation. We identify a composite set of 'shocks' in the NKPC that are contemporaneously outside the control of the firm. However, some of these exogenous elements are nevertheless endogenous to the firm through time. A classic example of such a predetermined variable is, of course, the capital stock. However, richer environments may indicate that other variables should similarly be modelled as endogenous but predetermined variables. For instance, one candidate may be the nominal wage rate. Our approach to the NKPC makes clear just how such a variable would impact on inflation and output. Our NKPC is therefore explicitly driven by inter alia 'supply' shocks and provides a more natural formulation to examine issues of monetary policy trade-offs within a model that can also account for a large number of stylized facts of aggregate business cycle fluctuations. ${ }^{8}$

\footnotetext{
${ }^{8}$ In related work, see Chadha and Nolan (2002), we examine a variety of monetary policy rules
} 
This explicit formulation of the NKPC places us in a better position to take the model to the data. And indeed econometric modelling of inflation within our framework also seems to offer some improvement on existing work. We use our structural form of the NKPC to generate forecasts of our 'activity' variable, which includes output, in the forward-looking manner of Campbell (1987). That approach generates a equiproportional restriction on the relationship between the current period discounted forecasts of activity and inflation, with the aggregate degree of price stickiness estimated as a free variable. In so doing, we track inflation very closely and infer a degree of aggregate price stickiness that appears both reasonable and consistent with existing estimates in the literature. ${ }^{9}$

The rest of the paper is structured as follows. Section 2 discusses in some detail the modelling of the supply-side of a benchmark New Keynesian model, including the factor markets. We then derive an approximate linear model in which inflation is shown to result from firms' price setting in response to pro-cyclical marginal costs. We then show in section 3 how the relationship between inflation and output is derived and make some points on the form that optimal price setting behavior takes. Section 4 takes our formulation of the NKPC to the data and assesses its empirical performance. We argue that our model tracks the data well provided we are also willing to accept that firms re-set prices, on average, every 1-3 quarters. Unfortunately, little direct evidence has been collected on UK data for this, but such an estimate is broadly consistent with the US data. Section 5 concludes and offers some thoughts for future work.

\section{A Benchmark Keynesian Model of Aggregate Supply}

In this section we derive the NKPC. Partly to keep our exposition compact, we choose only to focus on the supply-side of the economy. However, since the equilibrium demand conditions are not central to the modelling of the NKPC, this omission is without loss of generality.

Consider an economy in which there exists a continuum of differentiated goods, each produced by a monopolistically competitive firm, which faces intermittent signals allowing it to change its posted price. Each period the economy experiences

using the Phillips Curve derived in this paper.

${ }^{9}$ See, for example, Sbordonne (2001). 
one of a finite set of events, $s^{t}$. At any time $t$ the economy has experienced a sequence of events such that $s^{t}=\left(s_{0}, s_{1}, \ldots, s_{t}\right)$ denotes the history of events up to and including period $t$. Looking forward from date 0 , the conditional probability of any particular $s^{t}$ history being realized is $\sigma\left(s^{t}\right) \mid s_{0}$, with $s_{0}$ given. For notational ease we shall simply denote this conditional probability as $\sigma\left(s^{t}\right)$. These goods can be aggregated using Dixit-Stiglitz preferences to yield a consumption basket. We assume that each firm produces, in period $t, c_{t}\left(i, s^{t}\right)$ units of output. The composite good just mentioned is then given by

$$
C\left(s^{t}\right)=\left(\int_{0}^{1} c\left(i, s^{t}\right)^{(\theta-1) / \theta} d i\right)^{\theta /(\theta-1)}
$$

where $\theta>1$. The firm faces prices for factor inputs determined in perfectly competitive markets. We also assume that the firm meets demand for its produce at the posted price whether or not the firm has been able to change its price in that period. As is well known the demand schedule facing firm $i$, and the price index for the composite good, are given by (2.2) and (2.3) respectively:

$$
\begin{gathered}
c\left(i, s^{t}\right)=\left(\frac{p_{t}\left(i, s^{t}\right)}{P\left(s^{t}\right)}\right)^{-\theta} C\left(s^{t}\right), \\
P\left(s^{t}\right)=\left(\int_{0}^{1} p\left(i, s^{t}\right)^{1-\theta} d i\right)^{1 /(1-\theta)} .
\end{gathered}
$$

We assume a constant returns to scale production function. Output, $Y\left(i, s^{t}\right)$, is subject to exogenous changes in factor productivity, $A\left(i, s^{t}\right)$, influencing the return to capital, $K\left(i, s^{t-1}\right)$, and labor $N\left(i, s^{t}\right)$ such that:

$$
Y\left(i, s^{t}\right)=A\left(i, s^{t}\right) F\left[K\left(i, s^{t-1}\right),\left(N\left(i, s^{t}\right)\right)\right]
$$

Our notation is intended to emphasize that the net capital stock available to the $i$ th firm for use in production in period $t$ is a predetermined variable, determined by the set of events up through $s^{t-1}$. Equilibrium labor supply, on the other hand, is determined taking into account the events through $s^{t}$. In keeping with much of the literature we assume that the firm faces costs of adjustment when investing, denoted 
by $\phi($.$) , which are increasing in investment and strictly concave. Let \nu\left(i, s^{t}\right)$ denote depreciation. The firm's capital stock, $K\left(i, s^{t}\right)$, therefore evolves in the following way:

$$
K\left(i, s^{t}\right)=\left(1-\nu\left(i, s^{t}\right)\right) K\left(i, s^{t-1}\right)+\phi\left(\frac{I\left(i, s^{t}\right)}{K\left(i, s^{t-1}\right)}\right) K\left(i, s^{t-1}\right) .
$$

There are a number of ways to characterize optimal behavior by the firm. King and Wolman (1996) suggest breaking the firm into three parts. One part of the firm minimizes costs given the requirement to meet all demand at the posted price. The second part formulates a dynamic program for investment, acting as a price-taker in the investment goods market, and taking as given the rental price of capital. Finally, for those firms so permitted, the optimal, or profit-maximizing, price is set. In fact the first two decision units can be 'lumped together' to form a dynamic cost minimization problem, leading to a slight alteration in the optimality conditions. However, for consistency, here we exposit the optimality conditions in a more familiar way.

The requirements for cost minimization result in :

$$
\begin{aligned}
& W\left(s^{t}\right)=\Lambda\left(s^{t}\right) \frac{\partial F\left(i, s^{t}\right)}{\partial N\left(i, s^{t}\right)} \\
& Z\left(s^{t}\right)=\Lambda\left(s^{t}\right) \frac{\partial F\left(i, s^{t}\right)}{\partial K\left(i, s^{t-1}\right)} .
\end{aligned}
$$

The optimality requirements covering the dynamic aspects of the firm's problem require that: ${ }^{10}$

$$
\begin{gathered}
\mu\left(s^{t}\right)=\Psi\left(s^{t}\right) \phi^{\prime}\left(\frac{I\left(i, s^{t}\right)}{K\left(i, s^{t-1}\right)}\right), \\
\left(\frac{1}{1+r}\right) \sum_{s^{t+1}} \sigma\left(s^{t+1} \mid s^{t}\right) \mu\left(s^{t+1}\right) Z\left(s^{t+1}\right)+\left(\frac{1}{1+r}\right) \sum_{s^{t+1}} \sigma\left(s^{t+1} \mid s^{t}\right) \Psi\left(s^{t+1}\right) \\
\times \sum_{s^{t+1}} \sigma\left(s^{t+1} \mid s^{t}\right)\left[1-\nu\left(i, s^{t}\right)+\phi\left(\frac{I\left(i, s^{t+1}\right)}{K\left(i, s^{t}\right)}\right)-\phi^{\prime}\left(\frac{I\left(i, s^{t+1}\right)}{K\left(i, s^{t}\right)}\right) \frac{I\left(i, s^{t+1}\right)}{K\left(i, s^{t}\right)}\right]=\Psi\left(s^{t}\right),
\end{gathered}
$$

${ }^{10}$ That is we envisage the profit maximisation problem where the criterion is: $\sum_{t=0}^{\infty} \sum_{s^{t}} \beta^{t}\left[\sigma\left(s^{t}\right) \mu\left(s^{t}\right)\left(Z\left(s^{t}\right) K\left(s^{t-1}\right)-I\left(s^{t}\right)\right]\right.$, that is total profits of the 'investment sector', and where the the optimisation is subject to the sequence of equations in (2.5). 
where $\sum_{s^{t+1}} \sigma\left(s^{t+1} \mid s^{t}\right)$ denotes the taking of expectations over our discrete probability space, $\mu\left(s^{t}\right)$ is the current value of marginal utility of consumption of the representative agent, $\Psi\left(s^{t}\right)$ is a Lagrange multiplier associated with (2.5), and is interpretable as Tobin's $q . \Lambda\left(s^{t}\right)$ is the Lagrange multiplier associated with (2.4) and interpretable as nominal marginal cost. $Z\left(s^{t}\right)$ and $W\left(s^{t}\right)$ are nominal rental prices associated with capital and labor respectively and set in competitive factor markets, as noted earlier, and where both are positively associated with nominal marginal cost. Equations (2.6) and (2.7) show that firms' optimal hiring is characterized by a situation in which, when price equals marginal cost, real rental prices are equal to marginal product. Equations (2.8) and (2.9) show that the marginal return to investment this period, in the form of higher output and lower costs of adjustment in subsequent periods, is weighed against foregone consumption this period.

Each period all firms behave identically, as regards the foregoing optimality conditions. However, as regards price setting behavior we follow Calvo (1983) and many subsequent analysts, e.g., Yun (1996), Woodford (1996), Gali and Getler (1999), and assume that those firms that receive a signal enabling them to set prices in period $t$ face the probability $\alpha(0 \leq \alpha<1)$ of having to live with the same decision next period. More generally, we assume that a firm that sets its price this period faces the probability $\alpha^{k}$ of having to charge the same price in $k$-periods time. Before, we can calculate the optimal pricing behavior we need to calculate the per period costs. These are given by:

$$
\Lambda\left(s^{t}\right) K\left(i, s^{t-1}\right) \frac{\partial F\left(i, s^{t-1}\right)}{\partial K\left(i, s^{t}\right)}+\Lambda\left(s^{t}\right) N\left(i, s^{t}\right) \frac{\partial F\left(i, s^{t}\right)}{\partial N\left(i, s^{t}\right)} .
$$

In other words, total costs are simply the product of factor demands and marginal products. Given our homogeneity assumptions, we can then write down period $t$ profits as;

$$
\Pi\left(i, s^{t}\right)=p\left(i, s^{t}\right)\left(\frac{p\left(i, s^{t}\right)}{P\left(s^{t}\right)}\right)^{-\theta} C\left(s^{t}\right)-\Lambda\left(s^{t}\right)\left(\frac{p\left(i, s^{t}\right)}{P\left(s^{t}\right)}\right)^{-\theta} C\left(s^{t}\right) .
$$

The firm has to choose its optimal price, ${ }^{11}$ which is denoted by $p^{\prime}\left(s^{t}\right)$, as a function of future cost and demand condition facing the firm, and given a mark-up determined

\footnotetext{
${ }^{11}$ That is, the maximand facing such a firm is given by $\underset{\left\{p^{\prime}\left(s^{t}\right)\right\}}{\operatorname{Max}} \Pi\left(i, s^{t}\right)=$ $\sum_{k=0}^{\infty} \sum_{s^{t}}\left[\beta^{k} \frac{\mu\left(s^{t+k)}\right.}{\mu\left(s^{t}\right)}\left(p\left(i, s^{t}\right)\left(\frac{p\left(i, s^{t}\right)}{P\left(s^{t+k}\right)}\right)^{-\theta} C\left(s^{t+k}\right)-\Lambda\left(s^{t+k}\right)\left(\frac{p\left(i, s^{t+k}\right)}{P\left(s^{t+k}\right)}\right)^{-\theta} C\left(s^{t+k}\right)\right)\right]$.
} 
by preferences, $\frac{\theta}{(\theta-1)} \cdot{ }^{12}$ The optimal price is therefore given by,

$$
p^{\prime}\left(s^{t}\right)=\frac{\theta \sum_{k=0}^{\infty}(\alpha \beta)^{k} \sum_{s^{t}} \sigma\left(s^{t}\right)\left(\mu\left(s^{t+k}\right) P^{\theta}\left(s^{t+k}\right) C\left(s^{t+k}\right) \Lambda\left(s^{t+k}\right)\right)}{(\theta-1) \sum_{k=0}^{\infty}(\alpha \beta)^{k} \sum_{s^{t}} \sigma\left(s^{t}\right)\left(\mu\left(s^{t+k}\right) P^{\theta-1}\left(s^{t+k}\right) C\left(s^{t+k}\right)\right)} .
$$

The evolution of the aggregate price-level is then given by a weighted average of predetermined and current period optimal prices:

$$
P\left(s^{t}\right)=\left\{(1-\alpha)\left[p^{\prime}\left(s^{t}\right)\right]^{1-\theta}+\alpha\left[P\left(s^{t-1}\right)\right]^{1-\theta}\right\}^{1 /(1-\theta)} .
$$

Note that each firm in the economy faces the problem as set out in stage 1; the firms are identical save for their differentiated products. Consequently, we take equations (2.4) to (2.9), without the $i$ index, to represent aggregate behavior. The stage 2 decision which is granted $(1-\alpha)$ of producers results in all producers choosing the same price since, as equation (2.12) shows, $p^{\prime}\left(s^{t}\right)$ is a function solely of aggregate, i.e., economy wide, variables. Consequently aggregate price level behavior is given by equations (2.12) and (2.13).

\subsection{The Approximate Linear Aggregate Model}

We assume that output takes a Cobb-Douglas form, $Y\left(s^{t}\right)=A\left(s^{t}\right) K\left(s^{t}\right)^{s_{k}}[(1+$ $\left.\gamma)^{t} N\left(s^{t}\right)\right]^{s_{n}}$, where $\gamma$ denotes labor-augmenting growth. Date $t$ variables are then detrended in the usual manner. E.g., $X\left(s^{t}\right) \equiv X\left(s^{t}\right) /(1+\gamma)^{t}$, and $(1+\gamma) K\left(s^{t}\right)=$ $(1+\gamma) K\left(s^{t}\right) /(1+\gamma)^{t+1}$, where we recall that the capital stock is predetermined. We further assume that depreciation is constant across firms and through time. We then log-linearize the equations around their non-stochastic steady-state. In what follows, then, all variables are interpretable as (percentage) deviations from steady state. Our linearized model is therefore given by the following equations. (2.6) and (2.7) become, respectively (2.14) and (2.15), such that marginal costs, total factor productivity and the relative scarcity of factors determine the rental price of factors:

$$
\begin{aligned}
& W\left(s^{t}\right)=\Lambda\left(s^{t}\right)+a\left(s^{t}\right)+s_{k}\left(k\left(s^{t-1}\right)-n\left(s^{t}\right)\right), \\
& Z\left(s^{t}\right)=\Lambda\left(s^{t}\right)+a\left(s^{t}\right)+s_{n}\left(n\left(s^{t}\right)-k\left(s^{t-1}\right)\right) .
\end{aligned}
$$

\footnotetext{
${ }^{12}$ Note that the firms' mark-up, $\theta /(\theta-1)$, is constant in this set-up.
} 
Equations (2.8) and (2.9) become:

$$
\begin{gathered}
i\left(s^{t}\right)=-\eta\left(c\left(s^{t}\right)+\psi\left(s^{t}\right)\right)+k\left(s^{t-1}\right) \\
(1+\gamma) \psi\left(s^{t}\right)=\frac{1-\nu}{1+\delta} \sum_{s^{t+1}} \sigma\left(s^{t+1} \mid s^{t}\right) \psi\left(s^{t+1}\right)+\frac{i / k}{\eta(1+\delta)} \sum_{s^{t+1}} \sigma\left(s^{t+1} \mid s^{t}\right)\left(k\left(s^{t}\right)-i\left(s^{t+1}\right)\right) \\
+\frac{\mu(\delta+\nu)}{1+\delta} \sum_{s^{t+1}} \sigma\left(s^{t+1} \mid s^{t}\right)\left(Z\left(s^{t+1}\right)-c\left(s^{t+1}\right)\right)
\end{gathered}
$$

The capital accumulation equation (2.5) becomes

$$
(1+\gamma) k\left(s^{t}\right)=(1-\nu) k\left(s^{t-1}\right)+\phi\left(\frac{i\left(s^{t}\right)}{k\left(s^{t-1}\right)}\right) k\left(s^{t-1}\right) .
$$

We can denote inflation, in the region of steady state, by

$$
\pi\left(s^{t}\right) \equiv \frac{d p^{\prime}\left(s^{t}\right)}{p}-\frac{d p\left(s^{t}\right)}{p},
$$

and then it follows that (2.13) becomes

$$
\pi\left(s^{t}\right)=\frac{1-\alpha}{\alpha} p^{\prime}\left(s^{t}\right),
$$

so that current inflation is proportional to this period's optimal price, but a decreasing function of $\alpha$ for a given $p^{\prime}\left(s^{t}\right)$. Equation (2.12), in conjunction with (2.20), becomes

$$
\pi\left(s^{t}\right)=\beta \sum_{s^{t+1}} \sigma\left(s^{t+1} \mid s^{t}\right) \pi\left(s^{t+1}\right)+\frac{(1-\alpha)(1-\alpha \beta)}{\alpha} \Lambda\left(s^{t}\right) .
$$

It is clear to see that Equations (2.20) and (2.21) imply that the optimal markup increases in price rigidity and expected inflation but falls in marginal cost. ${ }^{13}$ Equation (2.21) is, of course, the NKPC in inflation-marginal cost space. Finally (2.4) the Cobb-Douglas output equation becomes:

$$
y\left(s^{t}\right)=a\left(s^{t}\right)+s_{n} n\left(s^{t}\right)+s_{k} k\left(s^{t-1}\right) .
$$

\footnotetext{
${ }^{13}$ That is $p_{t}^{\prime}-\Lambda_{t}=\alpha \beta\left(\frac{E_{t} \pi_{t+1}}{1-\alpha}-\Lambda_{t}\right)$.
} 


\section{Deriving The New Keynesian Phillips Curve}

Constructing a log-linear NKPC in inflation-output space is now a straightforward exercise in substitution. The output term enters (2.21) along with a composite shock that is a set of precise components, rather than an arbitrary series of 'cost' shocks. To see this note that since the capital stock is pre-determined in period $t, k\left(s^{t-1}\right)$, the equilibrium demand for labor is reflected in (2.22). In addition, equation (2.14) provides an expression for nominal marginal cost. Combining these observations with (2.21), we see that:

$$
\pi\left(s^{t}\right)=\beta \sum_{s_{t+1}} \sigma\left(s^{t+1} \mid s^{t}\right) \pi\left(s^{t+1}\right)+\kappa y\left(s^{t}\right)+\varphi x\left(s^{t}\right),
$$

where,

$\kappa \equiv \frac{(1-\alpha)(1-\alpha \beta)}{\alpha} \frac{s_{k}}{s_{n}}, \varphi \equiv-\kappa / s_{k}$, and, $x\left(s^{t}\right) \equiv\left(a\left(s^{t}\right)+s_{k} k\left(s^{t-1}\right)-s_{n} w\left(s^{t}\right)\right)$. The exogenous term, $x\left(s^{t}\right)$, is evidently neither a pure supply or cost shock, although it comprises familiar elements under these two categories. On the one hand total factor productivity, $a\left(s^{t}\right)$, is present acting to reduce the 'spread' between $\pi\left(s^{t}\right)$ and $\kappa y\left(s^{t}\right)$. On the other hand, there are effects from what may be labelled 'cost' shocks. In our set-up these operate via the term in $w\left(s^{t}\right)$, which here acts to increase $\pi\left(s^{t}\right)-\kappa y\left(s^{t}\right)$. The (pre-determined) capital stock is also included in our composite exogenous term, pushing down on the difference between inflation and output. It is also worth noting that the form that $x\left(s^{t}\right)$ has assumed in the present model is likely to be similar across richer specifications. One can envisage developing richer models of the labor market (e.g., see the imperfectly competitive model of Erceg et al.,1999) or investment goods market (e.g., where sticky goods prices impact the optimal investment program, Woodford, 2000), without altering the basic form of $x\left(s^{t}\right)$; in a wide variety of alternative set-ups $x\left(s^{t}\right)$ is likely to remain a combination of supply, cost and predetermined variables.

We have derived a NKPC that agrees with much of the extant literature in that the representative firm re-prices its output when a signal is received. That prices do not move completely to offset changes in marginal costs, tells us that our formulation is consistent with the notion of counter-cyclical mark-ups. ${ }^{14}$ But we are also able

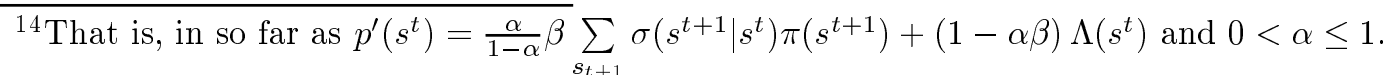


to show that the re-pricing is strictly proportional to a composite variable whose elements are contemporaneously outside the firm's control and therefore are crucial to current period output. Finally, we note that the stochastic evolution of inflation is likely to be procyclical in this model, with time series properties determined solely by the current level, and expected evolution, of $\left(y\left(s^{t}\right)-x\left(s^{t}\right) / s_{k}\right) .{ }^{15}$ We now proceed to examine the extent to which this NKPC can provide a description of the UK inflation data.

\section{Testing the foundations of the NKPC}

The key equation (3.1) shows that inflation this period is a function of anticipated inflation, contemporaneous activity and a composite term in wages, capital and total factor productivity. The inclusion of the forward-looking inflation term implies, in the usual way, that inflation at any time $t$ can be rewritten as:

$$
\pi_{t}=\beta^{T} E_{t} \pi_{t+T}+E_{t} \sum_{j=0}^{T-1} \beta^{j}\left(\kappa y_{t+j}+\varphi x_{t+j}\right),
$$

where we have simplified our notation in an obvious way. If we then constrain inflation to follow only the path dictated by 'fundamentals', then in the limit we find that

$$
\pi_{t}=E_{t} \sum_{j=0}^{\infty} \beta^{j}\left(\kappa y_{t+j}+\varphi x_{t+j}\right) .
$$

Inflation therefore is a function of the path of future anticipated output, as well as the path of the 'exogenous' term $x_{t}$. In what follows we shall, for convenience, call the $E_{t} \sum_{j=0}^{\infty}\left\{\beta^{j}\left(\kappa y_{t+j}+\varphi x_{t+j}\right)\right\}$ term our 'activity' variable, although it should be borne in mind that it comprises, output, productivity, cost, and contemporaneously pre-determined terms. Equation (4.2) establishes that any empirical investigation of the NKPC must incorporate expectations of the right hand side variables. In what follows we adopt the approach pioneered by Campbell (1987) and generate those expectations with a VAR representation of the process for inflation and its (forward-looking) determinants. To begin with it will be convenient to adopt the following redefinition, such that $\bar{\pi}_{t} \equiv \pi_{t}-\kappa y_{t}+\varphi x_{t}$. We therefore have that,

\footnotetext{
${ }^{15}$ Given that capital moves slowly at the business cycle frequencies, the additive shocks to inflation are output and wages minus TFP and so as long as $\frac{1}{s_{n}} a\left(s^{t}\right)<\frac{s_{k}}{s_{n}} y\left(s^{t}\right)+w\left(s^{t}\right)$ holds, which tends to be the case, inflation (and the new stream of optimal prices) will be procyclical.
} 


$$
\bar{\pi}_{t}=E_{t} \sum_{j=t+1}^{\infty} \beta^{j-t}\left[\kappa y_{j}+\varphi x_{j}\right] .
$$

They key insight of Campbell (1987) is that we are able to construct an expectation of the right hand side of equation (4.2) using a VAR to create forecasts of our real activity terms. To formulate these forecasts we use lags of marginal cost and of inflation to summarize all past periods' information on future real activity. The VAR is then written, suppressing constants, in first order form as: ${ }^{16}$

$$
\left[\begin{array}{c}
\kappa y_{j}+\varphi x_{j} \\
\bar{\pi}_{j}
\end{array}\right]=\left[\begin{array}{ll}
\psi_{11} & \psi_{12} \\
\psi_{21} & \psi_{22}
\end{array}\right]\left[\begin{array}{c}
\kappa y_{j-1}+\varphi x_{j-1} \\
\bar{\pi}_{j-1}
\end{array}\right]+\left[\begin{array}{c}
\epsilon_{1 j} \\
\epsilon_{2 j}
\end{array}\right] .
$$

It is now a straightforward exercise to generate the required forecasts, since it is apparent that

$$
E_{t}\left[\begin{array}{c}
\kappa y_{j}+\varphi x_{j} \\
\bar{\pi}_{j}
\end{array}\right]=\left[\begin{array}{ll}
\psi_{11} & \psi_{12} \\
\psi_{21} & \psi_{22}
\end{array}\right]^{j-t}\left[\begin{array}{c}
\kappa y_{t}+\varphi x_{t} \\
\bar{\pi}_{t}
\end{array}\right] .
$$

In compact form we may write (4.4) as:

$$
\mathbf{z}_{j}=\boldsymbol{\psi} \mathbf{z}_{j-1}+\mathbf{u}_{j}
$$

The expectation of future real variables alone can then be written in the following form, where $\mathbf{e}$ is the indicator vector $\left[\begin{array}{ll}1 & 0\end{array}\right]$ :

$$
E_{t}\left[\kappa y_{j}+\varphi x_{j}\right]=\mathbf{e} \psi^{j-t} \mathbf{z}_{t}
$$

We can then write (4.2) with the accompanying null hypothesis that the matrix $\Phi$ is $\left[\begin{array}{ll}0 & 1\end{array}\right]$ :

$$
\bar{\pi}_{t}=\mathbf{e}(\beta \boldsymbol{\psi})(\mathbf{I}-\beta \boldsymbol{\psi})^{-1} \mathbf{z}_{t}=\Phi \mathbf{z}_{t}
$$

We use the VAR to generate our forecasts and hence to provide a comparison of the inflation prediction of our formulation of the NKPC to the actual inflation rate.

\footnotetext{
${ }^{16}$ When we estimate this VAR we test down sequentially from higher order formulations. We adopt first order form here purely for expositional simplicity.
} 


\subsection{Data and Estimation}

In order to take our derivation of the NKPC to the data we construct measures of each element of our real activity term. We use UK data from 1963:1 to 2000:4 provided by the Office of National Statistics. ${ }^{17}$ We measure output as gross value added, use the value added deflator as our measure of the aggregate price level, average hours in manufacturing and persons of working age allow us to measure labor inputs and the stock of capital is derived from the same sources. All quantities are adjusted to per capita terms using the numbers of people of working age (that is those lying in the age range of 16-59 for men and 64 for women). The parameter $s_{n}$, labor share, is constructed using three methods: (i) in terms of compensation solely from employment; (ii) to account additionally for income from self employment and (iii) to account for income from the market sector alone rather than including the government sector. ${ }^{18}$ Capital share is thus simply, $1-s_{n}$. To construct the Solow residual we invert equation (2.22). The rate of time preference is taken to be consistent with an annual real rate of $5 \%$. The probability of firms receiving a signal to change prices, $\alpha$, is a free parameter and one that we will infer, employing a likelihood criterion, from the data.

Figure 5.1 plots the inflation rate, our real activity series, constructed with labor share accounting for self-employment, and as a comparison detrended output. The plot provides a clear prelude to much of the work in this section. The time series properties of inflation seem much more closely aligned to output augmented by our composite shock term in productivity and 'costs' than to simply output alone. For example, visual inspection of the data strongly suggests that whilst detrended output may have been a good predictor of inflation for the early part of the 1970s, it has been somewhat less than perfect in the late 1980s or 1990s.

The test of our version of the NKPC is conducted in a number of stages. First, the lag length in the VAR, equation (4.3), is chosen with reference to a series of sequential $\log$ likelihood ratio tests. Here we test each of the activity terms, calculated with either employment alone or also comprising self-employment, and find that the lag

\footnotetext{
${ }^{17}$ All the data and codes used for estimation are available on request.

${ }^{18}$ We present results for (i) and (ii). The results for (iii) are available on request but provide no sigificant difference to those for (ii). Again the spreadsheets detailing this calculation are available on request.
} 
length of the VAR should be 5 quarters. Table 1 shows that we are able to reject the zero restrictions implied on the 4 th lag when we reduce the lag length from 5 to 4. We therefore present results for 5 lags.

Equation (4.2) suggests that the NKPC implies one way Granger causality running from inflation to real activity, and we test accordingly. The existence of Granger causality here is simply indicating that under the NKPC current period (forward-looking) inflation is a (discounted) distributed lead of future activity. Table 2 provides clear evidence that inflation is indeed found to Granger cause real activity, that is provides statistically significant information concerning future activity, whereas the reverse is largely rejected.

We move on to estimate our VAR for the whole sample in the period from 1980. From the earlier discussion, we re-iterate that the forward-looking test of the NKPC includes a joint test of the parameter $\alpha$ and whether the discounted present value of expected real activity drives current inflation alone. We use a benchmark (unrestricted) model to infer an estimate of $\alpha$. We find that for real activity measured with self employment income, the estimates for both sub-samples are insignificantly different from one another at around $0.45 .^{19}$

We then restrict $\kappa$ - a parameter that is a function of $\alpha$ - to lie in a plausible range such that $\alpha$ is between 0.1 and 0.9. Figure 5.2 shows the results of this grid search for the estimates obtained over the full sample. The central estimate (bold line) of $\alpha$ at 0.45 implies that the $\Phi$ matrix will forecast inflation with a parameter of 1 . The White heteroscedasticity adjusted standard errors (dashed lines) suggest that we can be $95 \%$ certain that $\alpha$ lies in the range 0.4 and 0.7 . Figure 5.2 clearly shows that our version of the NKPC can be accepted along with a degrees of price stickiness that imply 1-3 quarters of aggregate fixed prices.

Finally, Table 4 shows the application of the non-nested choice tests of Vuong (1989) in order to choose across models with different $\alpha$ parameters. Briefly, these tests compare the maximized values of the log-likelihood and information criteria respectively under two alternative models. In this case we start from $\alpha=0.5$ and ask whether under sequentially higher alternatives i.e. as $\alpha$ tends to one, we are

\footnotetext{
${ }^{19}$ The results of the VAR1 lack parameter constancy in the estimate of $\alpha$ because if we do not adjust for self employment income we introduce a downward trend into the path $s_{n}$ in the 1980s. This biases up the coefficient of lagged inflation on marginal cost and hence the measure $\alpha$ in the 1980s. We therefore concentrate our exposition on the results of VAR2.
} 
gaining information. We use the version of the test where other models are known functions of the dependent variable. We find that as we go further from $\alpha=0.5$ the likelihood criterion does not suggest any advantage in selecting the alternative model. On the basis of these tests, then, we conclude that it is possible to accept a close approximation to the NKPC derived by modelling factor markets along with $\alpha$ in the range of $0.4-0.7$, and most probably in the lower half of that range.

Figure 5.3 plots the inflation rate consistent with our preferred formulation of the NKPC along with profiles consistent with significantly higher and lower degrees of price rigidity. We note the requirement for a different scale for $\alpha=0.1$ (the left-hand scale), that is where prices are essentially fully flexible. Similarly, there is a very clear indication of excessively rigid inflation rates once price-changing signals are modelled as being received on a frequency of 8-9 quarters, i.e. $\alpha=0.9$. In other words, our model require some significant but not outlandish degree of price stickiness in order to provide an acceptable match to the data; we find that we can capture much of the action in the aggregate data on the assumption that in the aggregate firms receive such signals in the region of every 1-3 quarters.

\subsection{Final Results}

Figure 5.4 illustrates the evidence that the VAR-based forecasts of real activity predict current inflation very closely. Table 5 illustrates the moments of predicted inflation for plausible values of $\alpha$ with actual inflation. We find that $\alpha$ in the region of 0.4-0.6 matches the moments of actual inflation closely. Compare this result with much of the extant literature that questions the empirical validity of the NKPC (see, for example, Fuhrer and Moore 1995 and Ball. 2000). Certainly there is no question of forecasting the wrong sign in inflation with our model and our estimated degree of price stickiness allows us to capture adequately the time series properties of inflation. But for a given mean we find that predicted inflation is somewhat more volatile than actual inflation. For example, from 1980 onwards, our model predicts a mean inflation rate of $7.06 \%$, compared with an actual mean rate of $7.09 \%$. On the other hand, we see that the actual standard deviation was 5.09, compared with a predicted value of 6.70. Looking over the whole sample from 1963 onwards (details available on request), we find that the actual and predicted mean inflation rates line up exactly at $7.06 \%$. We also find that the difference between actual (5.8) and 
predicted (6.7) standard deviation narrows somewhat compared with the shorter sample (by almost one percentage point), although clearly this difference remains an issue.

This 'excess volatility' in the NKPC prediction of inflation results directly from high estimated persistence in the marginal cost and inflation series. Although the unit coefficient in matrix $\Phi$ can be accepted we cannot exclude the possibility that some information for future inflation is provided by lagged marginal costs. There are two possible explanations here. First that the significant coefficients on marginal cost for current period inflation suggest that current period inflation is still adjusting to previous periods' marginal costs. Second that the marginal costs are picking up other bits of agents' information set required to forecast future marginal costs that inflation cannot - recall that our VAR is parsimonious. We leave this question to future research, noting simply that our current formulation offers a first order pass on the mapping from theory to data.

To sum up our model realistically captures $\alpha$ and various moments of actual inflation. And the close approximation to actual inflation is striking for such a simple model. Our main results suggest that by modelling factor markets we are able to understand within the framework of the NKPC the link between current inflation and current output. This theoretical link is backed up with a substantial amount of empirical support.

\section{Concluding Remarks}

A substantial amount of recent work in macroeconomics (both theoretical and policyoriented) has incorporated price-stickiness, generally invoking the time-dependent framework of Calvo (1983). Such models have given rise to a relationship linking inflation and output that nevertheless receives little or no support when taken to the data. Our derivation of the NKPC is simple and intuitive and clarifies the link between inflation and output. In doing so, it highlights the relative roles played by productivity, cost and predetermined variables. This is an important link, since rules of thumb which simply use output as a proxy for marginal cost have been of little use in modelling inflation.

Our empirical application of the model seems to deliver some notable successes. 
We can track well mean inflation, and visual inspection of actual and simulated data reveals a surprisingly close correlation for such a simple model. On the other hand, the model somewhat over-predicts the standard-deviation of inflation. We suggested, but did not investigate in this paper, that extending these models to incorporate effects from lagged activity may be an important task for future research. 


\section{References}

[1] Ball, L S (2000), 'Near-Rationality and Inflation in Two Monetary Regimes', NBER Working Paper No. 7988.

[2] Campbell, J Y (1987), 'Does Saving Anticipate Declining Labor Income? An Alternative Test of the Permanent Income Hypothesis', Econometrica, 55(6), pp.1249-1273.

[3] Calvo, G A (1983), 'Staggered Prices in a Utility Maximising Framework', Journal of Monetary Economics, 12, pp.383-398.

[4] Clarida, R, J Galí and M Gertler (1999), 'The Science of Monetary Policy: A New Keynesian Perspective', Journal of Economic Literature, 37(4), December.

[5] Chadha, J S and C Nolan (2001), 'Inflation and Price Level Targeting in a New Keynesian Model', forthcoming in the Manchester School.

[6] Erceg, C J, D W Henderson and A T Levin (2000), 'Optimal Monetary Policy with Staggered Wage and Price Contracts', Journal of Monetary Economics, 46(2), pp.281-313.

[7] Fuhrer, J and G Moore (1995), 'Inflation Persistence', Quarterly Journal of Economics, 110(10), pp.127-159.

[8] Galí J, and M Gertler (1999), 'Inflation Dynamics: A Structural Econometric Analysis', Journal of Monetary Economics, 44(1), pp.195-222.

[9] King R G and M Watson (1996), 'Money, Prices, Interest Rates and the Business Cycle', Review of Economics and Statistics, 78, pp.35-53.

[10] King R G and A L Wolman (1996), 'Inflation Targeting in a St. Louis Model of the 21st Century' NBER Working Paper No. 5507.

[11] Mankiw, N G and R Reis (2001), 'Sticky Information Versus Sticky Prices: A Proposal to Replace the New Keynesian Phillips Curve', mimeo, Harvard University. 
[12] Roberts, J M (1995), 'New Keynesian Economics and the Phillips Curve', Journal of Money, Credit and Banking, 27(4), pp.975-984.

[13] Sbordonne, A (2001), 'Prices and Unit Labor Costs: A New Test of Price Stickiness', mimeo, Rutgers University.

[14] Vuong, Q.H. (1989), 'Likelihood Ratio Tests for Model Selections and NonNested Hypotheses', Econometrica, 57, pp.307-33.

[15] Woodford, M (1996), 'Control of the Public Debt: A Requirement for Price Stability?,' NBER Working Paper No. 5684.

[16] Woodford, M (2000), 'Inflation Stabilization and Welfare', mimeo, Princeton University.

[17] Yun, T (1996), 'Nominal Price Rigidity, Money Supply Endogeneity and Business Cycles', Journal of Monetary Economics, 37, pp.345-370. 


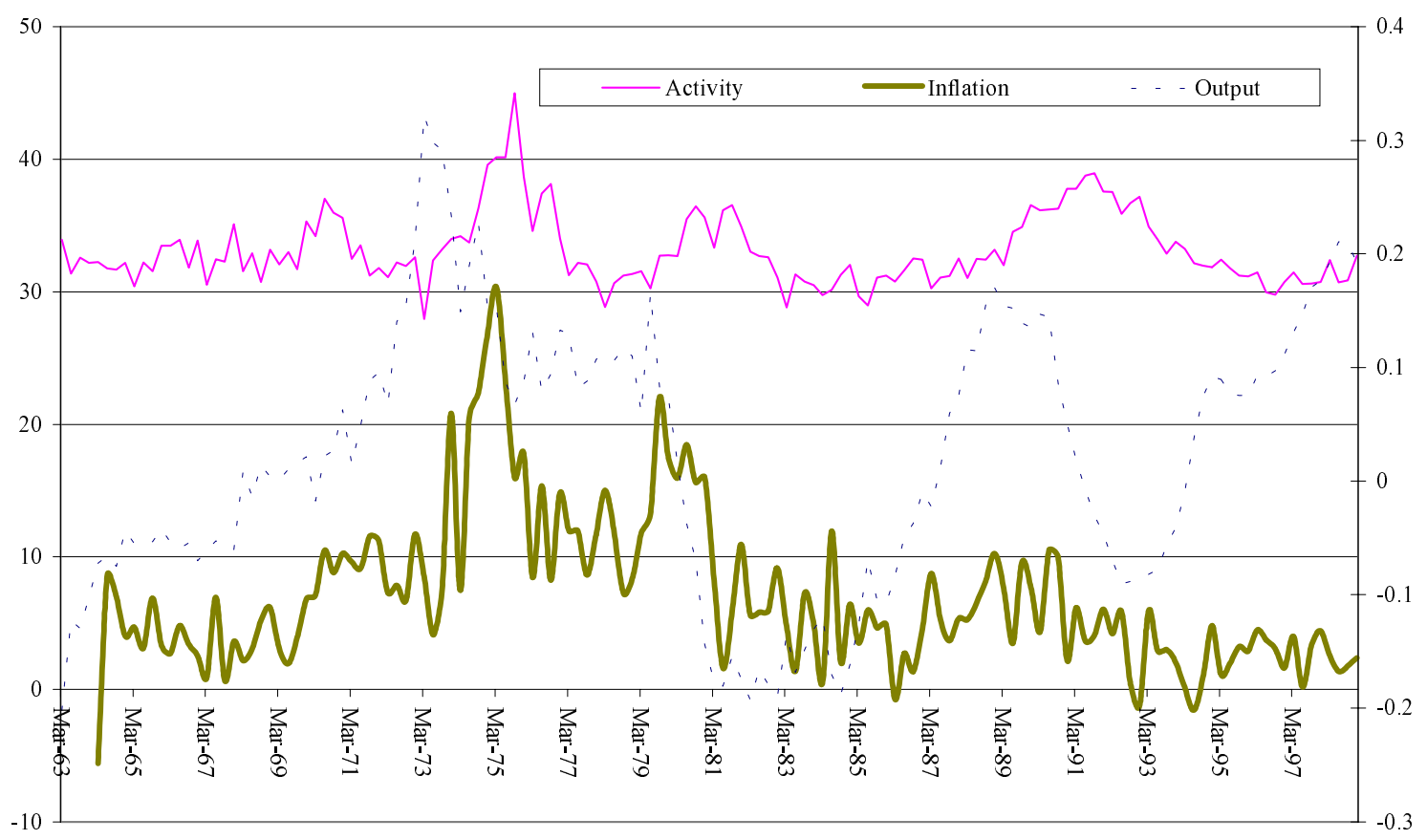

Figure 5.1:

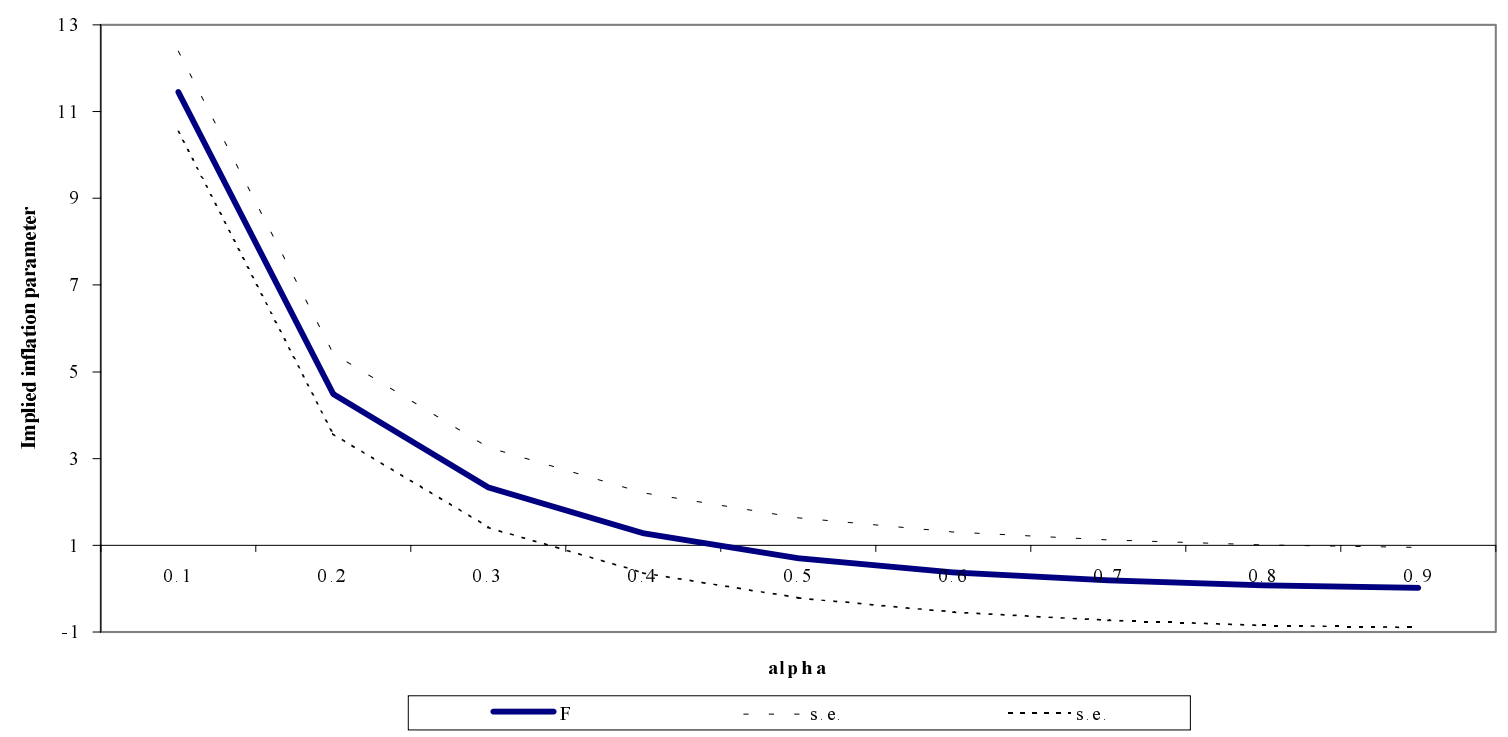

Figure 5.2: Price stickiness (x-axis) and proportionality with inflation (y-axis) 


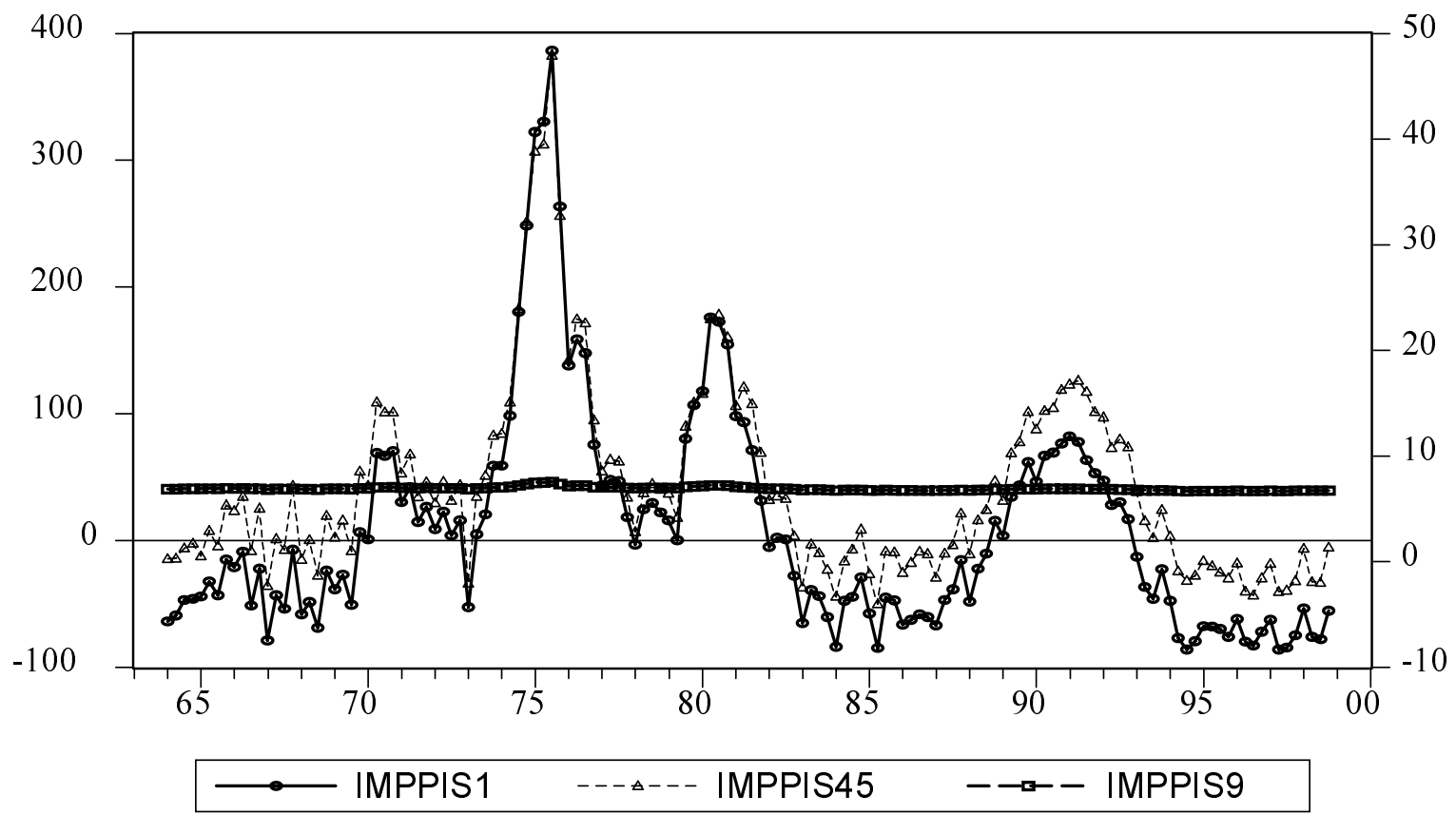

Figure 5.3: Comparing NKPC inflation under different levels of price stickiness $\alpha=0.1,0.45,0.9$.

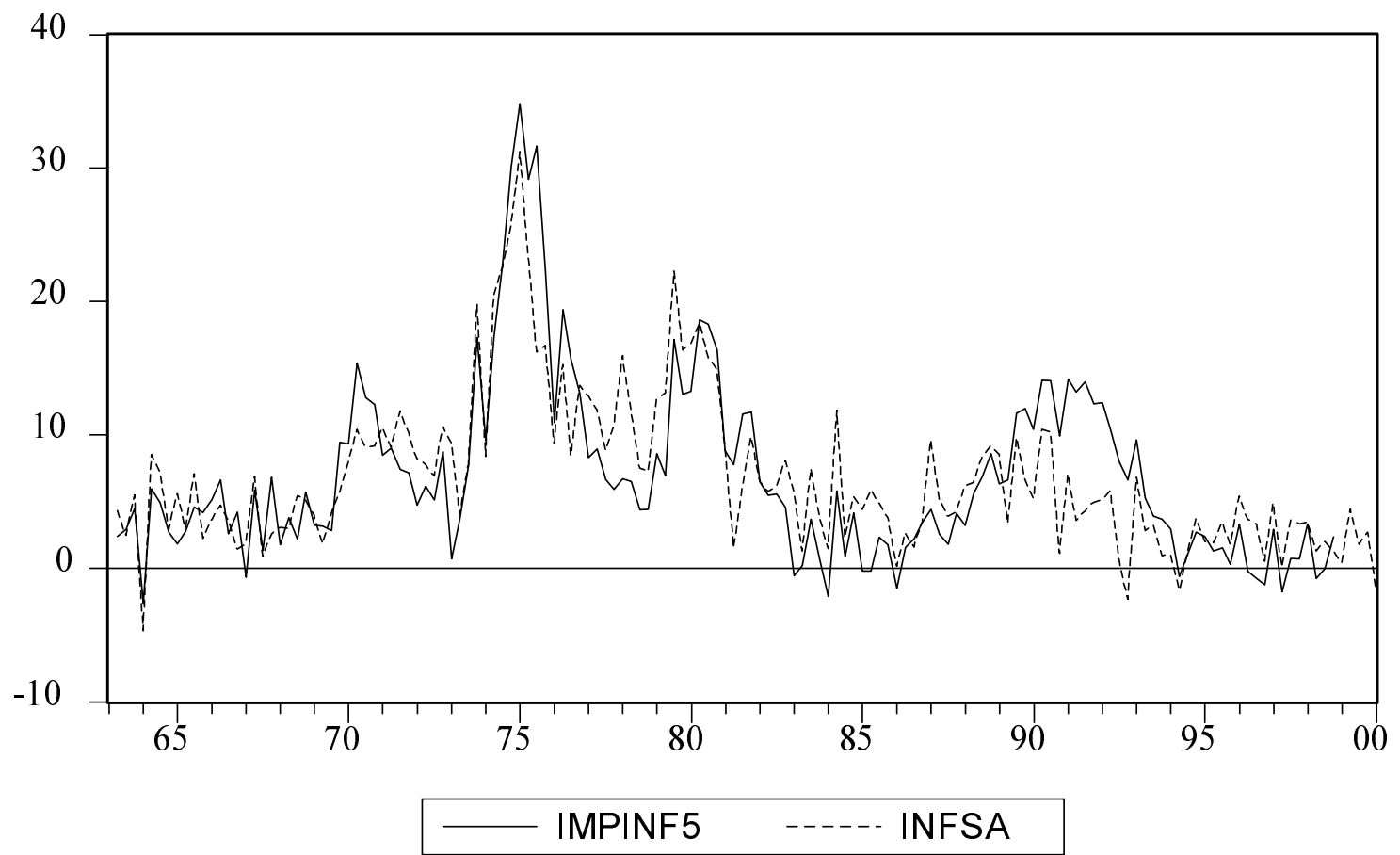

Figure 5.4: Comparing NKPC inflation ( $\alpha=0.5$, the solid line) and actual inflation. 


\section{Table $1 \quad$ Order of VAR Model}

\begin{tabular}{ccccc}
\hline \hline Lag Length & \multicolumn{2}{c}{ VAR1 } & \multicolumn{2}{c}{ VAR2 } \\
& LR Test & Adj LR Test & LR Test & Adj LR Test \\
7 & $5.28[0.260]$ & $4.60[.331]$ & $3.94[.414]$ & $3.44[.488]$ \\
6 & $9.12[.333]$ & $7.94[.439]$ & $7.80[.453]$ & $6.80[.559]$ \\
5 & $18.02[.115]$ & $15.70[.206]$ & $15.36[.222]$ & $13.38[.342]$ \\
4 & $81.52[.000]$ & $71.02[.000]$ & $85.07[.000]$ & $74.11[.000]$ \\
3 & $92.90[.000]$ & $80.93[.000]$ & $92.57[.000]$ & $80.65[.000]$ \\
2 & $104.53[.000]$ & $91.07[.000]$ & $104.47[.000]$ & $91.02[.000]$ \\
1 & $142.08[.000]$ & $123.78[.000]$ & $138.88[.000]$ & $121.00[.000]$ \\
0 & $637.09[.000]$ & $555.04[.000]$ & $597.42[.000]$ & $520.48[.000]$ \\
\hline
\end{tabular}

Note: VAR1 refers to marginal cost measured with employment income and VAR2 also comprises income from self employment. The test statistics are distributed as $\chi^{2}$ and p-values are given in brackets.

Table 2 Granger Causality Tests

\begin{tabular}{ccccc}
\hline \hline Lag Length & \multicolumn{2}{c}{ VAR1 } & \multicolumn{2}{c}{ VAR2 } \\
& $\mathrm{pi} \rightarrow \mathrm{mc}$ & $\mathrm{mc} \rightarrow \mathrm{pi}$ & $\mathrm{pi} \rightarrow \mathrm{mc}$ & $\mathrm{mc} \rightarrow \mathrm{pi}$ \\
7 & $3.38[0.003]$ & $1.29[.260]$ & $2.74[.011]$ & $1.31[.253]$ \\
6 & $4.12[.001]$ & $1.197[.313]$ & $3.505[.003]$ & $1.34[.243]$ \\
5 & $4.12[.002]$ & $2.13[.0 .067]$ & $3.76[.003]$ & $2.36[.0 .044]$ \\
4 & $5.67[.000]$ & $1.44[.223]$ & $5.05[.001]$ & $1.049[.385]$ \\
\hline
\end{tabular}

Note: VAR1 refers to marginal cost measured with employment income and VAR2 also comprises income from self employment. The test statistics is an F-stat and p-values are given in brackets. 
Table 3 Benchmark VAR Models

\begin{tabular}{|c|c|c|c|c|}
\hline & \multicolumn{4}{|c|}{ VAR1 } \\
\hline & \multicolumn{2}{|c|}{$1963-2000$} & \multicolumn{2}{|c|}{$1980-2000$} \\
\hline$\sum \psi_{11}$ & \multicolumn{2}{|c|}{$0.897[.054]$} & \multicolumn{2}{|c|}{$0.763[.054]$} \\
\hline$\sum \psi_{12}$ & \multicolumn{2}{|c|}{$0.020[.029]$} & \multicolumn{2}{|c|}{$0.081[.030]$} \\
\hline$\sum \psi_{21}$ & \multicolumn{2}{|c|}{$0.022[.056]$} & \multicolumn{2}{|c|}{$-0.055[.010]$} \\
\hline$\sum \psi_{22}$ & \multicolumn{2}{|c|}{$0.959[.036]$} & \multicolumn{2}{|c|}{$0.918[.062]$} \\
\hline \multicolumn{5}{|l|}{-2} \\
\hline$R$ & 0.860 & 0.956 & 0.886 & 0.836 \\
\hline F-stat. & $83.57[.000]$ & $294.03[.000]$ & $59.10[.000]$ & $39.16[.000]$ \\
\hline Func. & $6.79[.009]$ & $0.312[.576]$ & $2.42[.120]$ & $0.56[.454]$ \\
\hline Norm. & $4.15[0.125]$ & $31.58[.000]$ & $0.89[.640]$ & $1.37[.503]$ \\
\hline Heter. & $28.24[.000]$ & $11.55[.001]$ & $4.30[.038]$ & $0.680[.409]$ \\
\hline$\alpha$ & \multicolumn{2}{|c|}{0.37} & \multicolumn{2}{|c|}{0.56} \\
\hline$\Phi$ & {$[2.430$} & $1.0]$ & {$[0.81$} & $1.0]$ \\
\hline
\end{tabular}

\begin{tabular}{|c|c|c|c|c|}
\hline \multirow{7}{*}{$\begin{array}{l}\sum \psi_{11} \\
\sum \psi_{12} \\
\sum \psi_{21} \\
\sum \psi_{12}\end{array}$} & \multicolumn{4}{|c|}{ VAR2 } \\
\hline & \multicolumn{2}{|c|}{$1963-2000$} & \multicolumn{2}{|c|}{$1980-2000$} \\
\hline & \multicolumn{2}{|c|}{$0.794[.068]$} & \multicolumn{2}{|c|}{$0.910[.053]$} \\
\hline & \multicolumn{2}{|c|}{$0.031[.040]$} & \multicolumn{2}{|c|}{$0.041[.047]$} \\
\hline & \multicolumn{2}{|c|}{$-0.063[.051]$} & \multicolumn{2}{|c|}{$-0.045[.054]$} \\
\hline & \multicolumn{2}{|c|}{$0.980[.035]$} & \multicolumn{2}{|c|}{$0.887[.051]$} \\
\hline & \multicolumn{4}{|c|}{-2} \\
\hline $\bar{R}$ & 0.734 & 0.957 & 0.836 & 0.950 \\
\hline F-stat. & $38.05[.000]$ & $296.62[.000]$ & $39.16[.000]$ & $141.89[.000]$ \\
\hline Func. & $1.05[.305]$ & $.002[.962]$ & $0.56[.454]$ & $4.46[.035]$ \\
\hline Norm. & $5.93[0.052]$ & $29.63[.000]$ & $1.37[.503]$ & $0.22[.897]$ \\
\hline Heter. & $21.86[.000]$ & $11.894[.001]$ & $0.68[.409]$ & $3.82[0.05]$ \\
\hline$\alpha$ & \multicolumn{2}{|c|}{0.45} & \multicolumn{2}{|c|}{0.49} \\
\hline$\Phi$ & {$[0.75$} & $1.0]$ & {$[2.70$} & $=1.0]$ \\
\hline
\end{tabular}

Note: VAR1 refers to marginal cost measured with employment income and VAR2 also comprises income from self employment. The standard errors of the regression are White's heteroscedasticity adjusted. The test statistics are distributed as $\chi^{2}$ and p-values are given in brackets. 
Table 4 Non-Nested Tests

\begin{tabular}{ccc}
\hline \hline & \multicolumn{2}{c}{$\alpha=0.5$} \\
& Sargan Test & Vuong Test \\
$\alpha=0.6$ & $0.0728[.000]$ & $14.7455 .[000]$ \\
$\alpha=0.7$ & $0.1679[.000]$ & $2.163[.031]$ \\
$\alpha=0.8$ & $.0337[.000]$ & $11.307[.0 .000]$ \\
\hline
\end{tabular}

Note: The test statistics is an F-stat and p-values are given in brackets. In each case the model with $\alpha=0.5$ is always preferred.

Table 5 Comparing Actual Inflation to Predicted

\begin{tabular}{ccccccc}
\hline \hline & $\mu$ & $\max$ & $\min$ & $\sigma$ & $\frac{\sigma^{3}}{\sigma^{2}}$ & $\frac{\sigma^{4}}{\sigma^{2}}$ \\
$\pi_{t}$ & 7.09 & 25.68 & 0.37 & 5.09 & 1.50 & 5.22 \\
$\bar{\pi}_{t} \mid \alpha=0.44$ & 7.56 & 90.53 & -18.02 & 20.84 & 1.71 & 6.47 \\
$\bar{\pi}_{t} \mid \alpha=0.45$ & 7.12 & 47.89 & -4.012 & 9.07 & 1.71 & 6.87 \\
$\bar{\pi}_{t} \mid \alpha=0.5$ & 7.06 & 37.22 & -1.20 & 6.70 & 1.70 & 6.86 \\
$\bar{\pi}_{t} \mid \alpha=0.6$ & 6.93 & 20.17 & 2.18 & 3.44 & 1.25 & 5.11 \\
$\bar{\pi}_{t} \mid \alpha=0.9$ & 6.91 & 7.56 & 6.67 & 0.17 & 1.29 & 5.21 \\
\hline
\end{tabular}

Note: The fifth column measures skewness, where a positive number means that the distribution has a long right tail. The six column measures kurtosis, where a number in excess of 3 tells us that the distribution is peaked (leptokurtic) relative to the normal. 